\title{
Desarrollo de las redes sociales como herramienta de marketing. Estado de la cuestión hasta 2015*
}

\author{
José Sixto García** \\ Recibido: 2014-09-20 Aprobado por pares: 2014-11-11 \\ Enviado a pares: 2014-10-08 Aceptado: 2014-12-02
}

\section{Resumen}

En este artículo se explica la evolución de los medios sociales hasta convertirse en un elemento casi imprescindible dentro de la gestión empresarial actual. Para llegar a esta conclusión se empleó una serie de técnicas de investigación de carácter cualitativo y cuantitativo. Se destacan las ventajas y características de la puesta en marcha de un Plan de Medios Sociales, y se argumentan y razonan los beneficios que supone para una organización la gestión adecuada de una estrategia en redes sociales.

Palabras clave: medios sociales; redes sociales, Plan de Medios Sociales, organización 2.0, community management.

* Artículo de investigación científica y tecnológica que tiene como origen la investigación desarrollada para la realización de la tesis doctoral Marketing y Comunicación. Catalogación y análisis de la nueva variable del marketing, defendida en la Universidad de Santiago de Compostela en 2011. A partir de esa exploración inicial se ha seguido observando y analizando el fenómeno de los medios sociales hasta el día de hoy con la finalidad de describir el panorama y poder obtener los resultados aquí presentados.

** Doctor por la Universidad de Santiago de Compostela - Instituto de Medios Sociales. dirección@institutomedios.com 


\title{
Development of Social Networking as a Marketing Tool. State of the Art, 2015
}

\begin{abstract}
This article describes why social media become an almost essential element in today's business management. In reaching this conclusion a number of qualitative and quantitative techniques were used. It highlights the advantages and features of the implementation of a Social Media Plan in order to argue and reason the benefits that a proper management of a strategy in social media provide to an organization.
\end{abstract}

Key words: social media, social networks, Social Media Plan, Organization 2.0, community management. 


\section{Introducción}

Internet es el mayor centro comercial del mundo. Ofrece de todo y a todas horas. Lo que no está en Internet no existe y solo lo que no existe es capaz de no estar en la red. Los usuarios, todavía, no han olvidado cómo se hacen las compras físicamente (la mayoría las siguen haciendo), pero una cosa es comprar y otra buscar información sobre lo que se quiere comprar. Ahora ya no compramos sin informarnos y sin antes comparar los productos, y para eso exigimos tiendas abiertas 24 horas todos los días del año. En esa búsqueda muchas cestas también se llenan.

En este centro comercial sin límites ni fronteras se vende de todo, desde un coche hasta un perfume, pasando por una creencia religiosa, un amor de los que perduran, un modo de vida, unas galletas para adelgazar o un curso de chino. Es el centro comercial más grande del mundo, pero al mismo tiempo el lugar donde es más fácil comparar precios y opiniones y donde la gente invierte más tiempo. Lo impulsivo funciona, pero lo meditado más.

Cuando entran al centro comercial algunos clientes ya saben en qué tienda está el producto que buscan. Sin embargo, la mayoría se para en el mostrador de Información y preguntan: ¿quién me ofrece lo que busco? Ese mostrador se llama Google y tiene la capacidad de abrir en menos de un segundo las puertas de todas las tiendas que tienen lo que buscamos o, por lo menos, algo parecido.

Las tiendas de la red también tienen escaparates. El principal, el que da a la avenida principal, es su portal corporativo y a través de él -si nada lo empaña- se ven todos los productos y servicios que hay en su interior. Sí, los servicios también, porque en las tiendas en red lo intangible es mucho más fácil de vender. Se escribe, se ve, suena, se materializa y se vende, como las rosquillas.

Los comercios más sofisticados tienen también un meeting point. La gente, al igual que en el centro comercial de toda la vida, pasa por allí a lucirse, a ver qué cae, a ver qué le recomiendan, a ver qué ha comprado su vecino, y su vecino a ver qué ha comprado él. Esos puntos de encuentros se llaman redes sociales y en ellos se comparten experiencias, se conoce a gente y se cuenta cómo le ha ido a uno en la tienda de al lado.

La gente que frecuenta este centro comercial es muy cotilla. Lo cuenta todo. A las tiendas que tratan bien a sus clientes les encanta que alguien les haga publicidad gratuita contando a diestro y siniestro que son una maravilla, pero las que no los tratan tan bien han visto cómo sus problemas aumentan, tienen pintadas en la puerta y el virus del boca a boca están convirtiendo lo que parecía un catarro en una gripe de encamar.

Nadie se calla nada. El centro comercial está infectado permanentemente de viralidad. Los virus se propagan con la misma velocidad que los robots de Google conducen a los clientes a la entrada de las tiendas. Este tipo de virus no es ni bueno ni malo, simplemente depende de cómo se sepa utilizar. Cuando lo que se propaga es positivo los efectos son magníficos, aunque el otro final del cuento consiste en que lo malo todavía se difunde más rápido que lo bueno. Luego están los que no difunden ni para bien ni para mal, pero 
esos, como dijimos, no existen. Estoy en las redes, entonces existo, diría Descartes si viviese en el siglo XXI.

\section{Evolución del marketing como técnica y disciplina hasta 2015}

En la evolución del marketing es especialmente relevante la extensión del concepto desde los escenarios estrictamente económicos y empresariales al marketing social y de las ideas, lo que supone que su aplicación se extendiese a todo tipo de empresas y organizaciones con independencia de su filosofía de actuación y de si tienen o no finalidad lucrativa.

Los diferentes enfoques y orientaciones vinculados al marketing desde esa primera etapa incipiente hasta su fase de consolidación - dejando patente el paso del enfoque basado fundamentalmente en la producción masiva hacia una orientación al mercado, al marketing-, dan como resultado un tipo de actividad que no solo pretende lograr los objetivos organizacionales, sino conseguir una sociedad mejor a largo plazo.

Analizar los propósitos y las finalidades del marketing supone, obligatoriamente, indagar en su propia naturaleza partiendo de las necesidades humanas, los deseos y las demandas. El tránsito de las carencias a su satisfacción mediante la consecución de productos deseados, teniendo en cuenta los conceptos esenciales del valor y la satisfacción de los usuarios como fines últimos del marketing exige entender las características y los rasgos distintivos de esos procesos de transacción e intercambio tanto en los terrenos tangibles como intangibles y las relaciones entre sí.

Con respecto a las relaciones, son las relaciones estables y consolidadas en el tiempo las que se han erigido como una de las premisas básicas del marketing actual desde la perspectiva de conseguir mayores beneficios para todas las partes implicadas en el intercambio, mejorando la satisfacción de cada una de ellas y dando lugar, por otro lado, a la consolidación del denominado marketing de relaciones como culminación de la evolución de un marketing de transacciones aisladas.

Esto deriva a su vez en la consecución de un tratamiento personal e individual a cada uno de los usuarios con los que se mantienen relaciones duraderas, lo que propicia el surgimiento del denominado marketing uno a uno o one to one. Las nociones de compromiso y confianza resultan condicionantes imprescindibles para la implementación del marketing moderno y también se trasladan esos conceptos al interior de las organizaciones para analizar su repercusión e incidencia en el marketing interno.

Al hablar del marketing en 2015 sigue siendo necesario recordar los elementos controlables e incontrolables desde su propio dominio. Dentro de los primeros nos referimos a las denominadas 4Ps (producto, precio, distribución y promoción) y a las diferentes ópticas, modalidades y tácticas que ayudan a estructurarlos de manera eficaz, sin olvidar que se deben complementar con otros indicadores menos afianzados pero que algunos estudiosos también han señalado como variables controlables del marketing (como son las relaciones públicas, la comunicación o las relaciones con la Administración). En la segunda categoría nos encontramos con el mercado, la competencia y el entorno de la organización como condicionantes no controlables para el dominio estratégico. 
Precisamente a partir del concepto de estrategia se han definido a lo largo de los últimos dos siglos tipos y opciones de aplicación para configurar un modelo de actuación diseñado desde el meollo de la organización que no permita actuaciones al azar y que recoja todo tipo de actividad en un conglomerado de acciones que definen la planificación estratégica. Suele ser habitual que a partir de la cabeza visible de la dirección de marketing se entronque la dirección estratégica en el propósito de lograr la globalidad de una organización 2.0 y su diseño mediante documentos de planificación debidamente estructurados y elaborados.

Desde esta perspectiva estratégica el marketing moderno exige tener en cuenta factores como la misión, los objetivos, las auditorías, el análisis DAFO, la cartera de negocios o los sistemas y mecanismos de seguimiento y control, y todo un conjunto de operaciones de marketing (marketing operacional) para su puesta en valor dentro de la planificación que ha de seguir la organización y la consiguiente aproximación de los productos al mercado y a los públicos a los que van dirigidos.

Existen, por otra parte, campos de actuación específicos donde el marketing precisa una adaptación particular para dar respuesta a la exigencia de un mercado concreto y, en este sentido, su aplicación en estos sectores también será particular y específica. Se trata del marketing de productos industriales, el marketing de servicios, el marketing no empresarial, el marketing internacional, el marketing ecológico o el marketing con causa. Dentro del marketing no empresarial encontramos el marketing de las instituciones sin ánimo de lucro, el marketing público, el marketing social y el marketing político y electoral. Estas adaptaciones particulares influyen en el marketing mix, en los productos, en los mercados y en las estrategias para determinar cuáles son los mejores senderos para una inestimable implementación.

Cualquiera de las modalidades anteriores y, por supuesto, el propio marketing tradicional, se optimizan mediante el soporte digital. La incidencia de Internet en el marketing y en los mercados tradicionales es incuestionable, lo que provoca un traspaso desde el marketing nacional al marketing global, donde la fidelización del usuario resulta todavía más importante y su consecución se logra mediante el seguimiento de un marketing continuo y la explotación de estrategias de viralidad que convierten a los usuarios en difusores de los contenidos y propagadores de las cualidades de los productos ofertados. El escenario de interactividad lo permite la denominada web 2.0, y sus diferentes formatos posibilitan la puesta en práctica de este tipo de marketing. Es justamente uno de esos formatos el que ha revolucionado el mundo del siglo XXI: las redes sociales.

\section{Metodología empleada}

El presente artículo puede definirse como una actualización o continuación de los resultados concluyentes presentados en la tesis doctoral Marketing y comunicación. Catalogación y análisis de la nueva variable del marketing, presentada y defendida en la Universidad de Santiago de Compostela en 2011. 
A partir de los datos obtenidos en esa primera exploración, se ha ido monotorizando de manera constante y continuada el fenómeno de las redes sociales en particular y de los medios sociales en general, empleando para ello una combinación de técnicas cuantitativas y cualitativas que han permitido descubrir las principales estrategias, acciones de comunicación y marketing, impacto y medición estadística de audiencias de las redes sociales generalistas y también de las principales especializadas o de corte vertical.

Como métodos de investigación de carácter cuantitativo se han empleado las bases de datos de medición de audiencias en medios sociales, apoyando los datos en una revisión bibliográfica del estado del arte. Con respecto a los métodos de investigación de carácter cualitativo se ha ejecutado la observación participante durante dos días alternos durante seis meses consecutivos en las redes más populares de nivel mundial.

Tabla 1. Metodología empleada

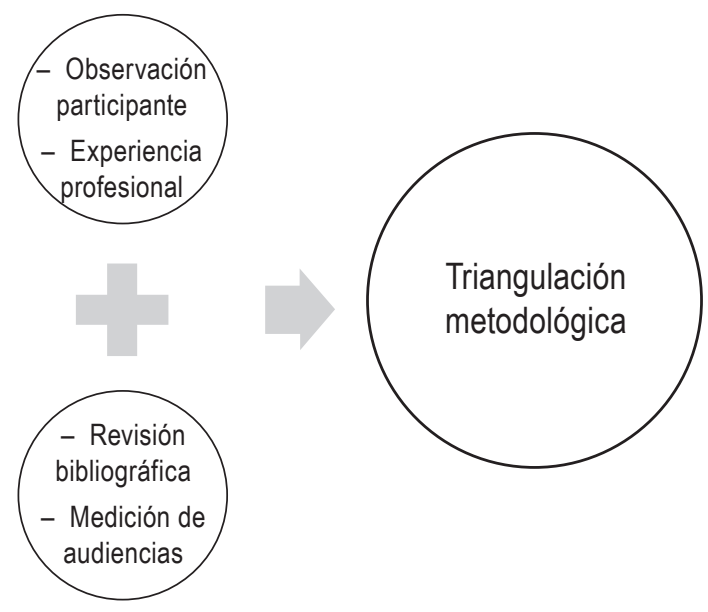

Fuente: elaboración propia

Fruto, pues, del empleo constante de esa triangulación metodológica, los resultados aquí presentados describen el panorama actual del marketing digital y sus canales de actuación más destacados, fundamentalmente las redes sociales. Ello permite extrapolar conclusiones de los beneficios que supone una gestión correcta y bien definida para las organizaciones actuales y de cómo su presencia web en redes mejora no solo su actividad SEO o de imagen -que no es poco-, sino cómo estas plataformas pueden contribuir a la mejora de sus cuentas de resultados.

\section{4. ¿Cómo son las organizaciones 2.0? Influencia de las redes en los modelos de gestión}

Las organizaciones se han visto obligadas a deshacerse de sus estructuras de comunicación rígidas y extremadamente jerárquicas porque ahora cualquier cliente -o cualquier empleado- puede abrir un blog o un perfil en una red social y contar lo que se le pase por 
la cabeza. El consumidor suele saber mejor lo que le conviene fabricar a una empresa que ella misma, y eso es un potencial enorme que hay que aprender a escuchar. Las sugerencias que se dejaban en el buzón se han multiplicado sin límite y la comunicación que salía sin retorno casi siempre retorna.

La comunicación 2.0 permite que la vida cotidiana se piense en términos de redes sociales como escenario de interactividad grupal e individual, como forma de organización pública y privada, y como manifestación unipersonal y colectiva. Lo que comenzó siendo una forma de manifestación virtual de la esfera interpersonal privada generó una nueva fórmula de relación social en la que hoy participan millones de personas en el mundo. Las redes sociales y la filosofía 2.0 se han integrado en todo tipo de organizaciones -con o sin ánimo de lucro, públicas o privadas- de manera que web 2.0 es también organización 2.0 (Túñez y Sixto, 2011).

La web 2.0 comenzó a plantearse como tal justo cuando surgieron en Internet herramientas gratuitas que permitían a cualquier usuario no avanzado crear y compartir contenidos sin tener que pagar el diseño de una página web (Fages-Ramió, 2008). Aunque los blogs empezaron a trazar el sendero, las redes sociales marcan un nuevo entorno y un nuevo soporte comunicativo con las personas y las organizaciones en un modelo de comunicación multidireccional. La red es global, aunque se articula con pequeñas redes en las que cada miembro decide a quién acepta en su grupo de interlocutores para interactuar con ellos. Por el volumen de participantes y por las condiciones de control sobre el mensaje, permiten la creación de una inteligencia colectiva a partir del intercambio de experiencias y conocimientos mediante herramientas de comunicación de uso sencillo.

Cuando nos referirnos a portales o medios sociales (social media), identificamos un conjunto de actividades que implican la creación de contenidos para compartirlos en Internet, principalmente, y cada vez más a través de las redes sociales. En este sentido, los medios sociales son herramientas, aplicaciones y plataformas cuyo objetivo principal es facilitar las relaciones entre usuarios, la interacción, la colaboración y la distribución de contenidos. La mayoría de las veces se usa el término social media para referirse a actividades que integran la tecnología, las telecomunicaciones móviles y la interacción social en forma de conversaciones, fotografías, imágenes, vídeos y pistas de audio.

La principal novedad que supone este tipo de plataformas con respecto a otras anteriores reside en el cambio de rol que padece el usuario. Los navegantes de Internet han dejado de recibir olas en su travesía para ser ellos mismos quienes crean esas olas y quienes chocan sus propios barcos con otros marinos. Los usuarios ya no solo son receptores, sino también creadores e intermediarios de contenidos.

Los flujos y las actitudes de la comunicación han cambiado. La universalización de la posibilidad de ser emisor de mensajes que lleguen a grupos numerosos a través de Internet ha provocado la ruptura del esquema tradicional de comunicación lineal y su sustitución por modelos circulares o en racimo en los que cualquier individuo puede ser receptor, y emisor o reemisor (Túñez y Sixto, 2011). Antes las marcas mandaban mensajes 
unidireccionales a un público masivo, pero ahora se les exige más, deben participar con el público y experimentar con él. Lo primero es conseguir la empatía con los usuarios; cuando se logra fidelizarlos el éxito se aproxima.

Las organizaciones actuales no pueden vivir en un mundo ajeno al de sus clientes y consumidores. Crear para nadie es absurdo, pero todavía es más irracional pensar que por fabricar un producto alguien va venir a nuestra puerta a preguntarnos ¿̇me lo vende? Nuestros competidores se están comiendo el mundo y no podemos permanecer impasibles. Los procesos de marketing online exigen que la organización interactúe con el usuario, lo que deriva en una inminente reducción de las barreras existentes entre ambos. La web 2.0 y los medios sociales que en ella se desarrollan, sobre todo las redes sociales, permiten la comunicación multidireccional y, en consecuencia, cualquier usuario puede aportar contenido y convertirse en prescriptor.

Así pues, desarrollar estrategias de marketing online en los medios sociales (o redes sociales) es imprescindible para sobrevivir en el mercado actual. Lo es porque tres de cuatro personas están usando los medios sociales, más de $2 / 3$ de la población global de Internet visita redes sociales; visitar sitios sociales es la segunda actividad en red (por encima de la consulta del correo electrónico); Facebook tiene más de 1100 millones de usuarios repartidos por todo el mundo; Twitter cuenta con más de 230 millones de usuarios activos y, sobre todo, porque el $93 \%$ de los usuarios de los medios sociales consideran que una empresa debería tener presencia en las redes sociales. Son datos de Plenum Media, The Internet Marketing School (2013).

Todas las organizaciones pretenden tener una cuenta de resultados saneada, con muchos ingresos y pocos gastos. Algunas piensan que esto se consigue esperando sentados o por arte de magia e ignoran los factores que influyen en la consecución de esa rentabilidad:

a) La reputación: ¿cómo nos perciben?

b) La notoriedad: ¿cuánto nos perciben?

c) La calidad del producto o servicio, resultado de la I+D+i.

d) La atención al cliente (CRM).

e) La alineación de la marca con los valores que identifican a los usuarios (conocimientos de tendencias).

f) La responsabilidad social corporativa o empresarial (RSC/RSE).

g) Los procedimientos productivos.

h) La gestión de los recursos humanos, su incentivación y su formación.

i) El marketing y la comunicación.

En una sociedad avanzada tecnológica y sociológicamente las organizaciones que no utilicen los nuevos soportes y técnicas de la comunicación cibernética están abocadas 
al fracaso. En esta esfera virtual las redes sociales son un recurso y un canal adecuado para la implementación del marketing porque crean un escenario donde es posible la interacción con los usuarios (Túñez y Sixto, 2011). El empleo de redes sociales por parte de una organización influye en todos los factores anteriores y, en consecuencia, en la mejora de los resultados generales. Si su uso está bien planificado y bien gestionado por un profesional las redes pueden ser útiles para mejorar las relaciones con los clientes actuales y conseguir otros nuevos, para crear una comunidad de usuarios en torno a la marca y para promocionar los productos en Internet de manera gratuita.

\subsection{Redes sociales: un elemento imprescindible en el Plan de Medios Sociales}

\subsection{1 ¿Qué?}

Desde el punto de vista sociológico una red social es un sistema abierto y en construcción permanente en forma de interacción social fundamentada en un intercambio dinámico entre personas, grupos e instituciones en diferentes contextos, pero que siempre comparten necesidades y que se organizan para potenciar sus recursos y competencias. La red social en red, valga la redundancia, es lo mismo, pero en Internet.

Los contactos de la red virtual no están obligados a conocerse en persona, simplemente tienen intereses comunes. Interactúan, aunque no se conozcan, y comparten sus preocupaciones, sus gustos y sus disgustos con sus amigos, con sus conocidos y los amigos de los amigos. A veces simplemente se ingresa a la red social para buscar a alguien que comparta nuestros gustos o que tenga opinión sobre algo que nos preocupa. Los medios sociales crean vínculos, pero a diferencia de las redes físicas, no requieren compromiso afectivo.

El Libro blanco de la comunicación en medios sociales, del International Adverstising Bureau (IAB, 2009), define los medios sociales como plataformas digitales de comunicación que dan el poder al usuario para generar contenidos y compartir información a través de perfiles privados o públicos. Esta denominación abarca las redes sociales, los blogs, los fotoblogs, los microblogs, las utilidades gráficas, los mundos virtuales, los agregadores de contenido y, en general, cualquier soporte que ofrezca a sus usuarios la posibilidad de generar contenido susceptible de ser compartido (Sixto, 2011).

\subsection{2 ¿Quién?}

El 1954 J. A. Barnes se refirió al concepto de social network para describir una estructura social de nudos que eran en general personas u organizaciones, de tal forma que una red social representaba las relaciones entre personas, grupos u organizaciones. Barnes se refería a las redes físicas y no a las virtuales, aunque la principal diferencia entre unas y otras es fundamentalmente el tamaño, puesto que mientras que el tamaño máximo de una red física no suele superar las 150 personas, las redes sociales en Internet pueden albergar a varios miles de miembros, a pesar de que la fortaleza del nexo existente entre ellos sea inferior. 
La concepción de las redes se extiende con la inauguración del telégrafo en Francia (1794: París-Lille) y está presente en la teoría del filósofo social Claude-Henri de Rouvroy, conde de Saint-Simon (1760-1825) y padre del socialismo francés. Para flexibilizar la rigidez del modelo de la burocracia administrativa de Weber, vuelven a recuperarse a partir de los años 70 del siglo XX las nociones sansimonianas de red y comunidad. La noción reticular (Miguel de Bustos, 2007) que surge en los siglos XIX y XX con la revolución de las comunidades vuelve a tener su translación política a la diplomacia global de las redes, que conceptualiza Zbigniew Brzezinski (1989), el consejero del presidente norteamericano James Carter.

\subsection{3 ¿Cómo?}

Las redes sociales sirven fundamentalmente para conectar a las personas entre sí, de tal forma que son el entretejido formado por las relaciones sociales que, desde los diferentes ámbitos de vida y con diferente grado de significación, vinculan a un sujeto con otro (Sixto, 2011). Su crecimiento ha sido espectacular en los últimos cinco años y hoy en día redes sociales como Facebook cuentan con más de 1100 millones de usuarios en todo el mundo.

La social network tiene su origen y posterior desarrollo en la teoría de los seis grados de separación, según la cual toda la población del planeta está conectada a través de no más de seis personas. La teoría fue inicialmente propuesta por el húngaro Frigyes Karinthy en 1929 y se basa en las denominadas chains o cadenas, un concepto asentado en la idea de que el número de conocidos crece exponencialmente con la suma de enlaces en la cadena.

Con un pequeño número de enlaces el conjunto de conocidos abarcaría a la totalidad de la población humana. La teoría, recogida también en el libro Six Degrees: The Science of a Connected Age, del sociólogo Duncan Watts, intenta demostrar que es posible acceder a cualquier persona con tan solo un máximo de seis saltos. Cada persona conoce de media -entre amigos, familiares o compañeros del trabajo o escuela- a unas 100 personas. Si cada uno de esos amigos o conocidos próximos se relaciona a su vez con otras 100 personas, cualquier persona podría enviar un mensaje a 10000 personas más por medio de sus contactos.

Esos 10000 individuos son contactos de segundo nivel, es decir, que el individuo no conoce pero que puede conocer fácilmente a través de los que sí conoce. Si esos 10 000 conocen a otros 100, la red se ampliaría a 1000000 de personas conectadas en el tercer nivel, a 100000000 en el cuarto, a 10000000000 en el quinto y a 1000000000 000 en el sexto nivel. En seis pasos y con las tecnologías disponibles se podría enviar un mensaje a cualquier persona del planeta.

En la práctica real encontramos, sin embargo, que el número de contactos del segundo nivel es sustancialmente menor a 10 000, puesto que es usual tener amigos comunes en las redes sociales, aparte de apreciar que cuantos más pasos sea necesario dar, más alejada será la conexión entre dos usuarios y, en consecuencia, más difícil y despreciable 
la comunicación, aunque en las redes virtuales este inconveniente es inferior al patentado en las redes físicas.

No se trata de comunicarse solo virtualmente, sino de comunicarse más y por canales diferentes y variados, lo que, por otra parte, aumenta la potencialidad viral del mensaje, que puede ser distribuido no solo por la fuente emisora, sino también por los propios receptores, en un paralelismo con el antiquísimo boca a boca.

Dunbar, Gamble y Gowlet (2009) -el primero de ellos director del Instituto de Antropología Evolutiva de Oxford- han establecido en 150 el número máximo de relaciones personales que un individuo puede establecer y gestionar de forma directa. No obstante, esa posibilidad aumenta de forma exponencial gracias a las nuevas tecnologías de la información y de la comunicación, de tal forma que una persona puede tener miles de relaciones a través de las redes e incluso formar parte de varias diferentes. En este sentido, las herramientas informáticas o de software social operan mediante la gestión de conocimiento compartido, la integración de comunidades y la cooperación (San Millán et al., 2008) para potenciar la eficacia de las redes sociales.

Las redes sociales suponen el salto de las relaciones presenciales propias de la familia, el barrio, la escuela o el club a las de carácter telepresencial y virtual. En esta línea, el concepto de red social es tan antiguo como la propia humanidad, lo que ocurre es que ahora cobra nuevos impulsos a medida que va convergiendo con los diferentes sistemas de comunicaciones, en concreto con las telecomunicaciones: primero el telégrafo, luego el teléfono y ahora Internet.

El fenómeno mediático actual de las redes sociales es un nuevo brote tras la crisis del crecimiento de Internet a comienzos de este siglo XXI. De los conocimientos, recursos humanos y redes de relaciones establecidas entre los informáticos afectados por la explosión de la burbuja virtual surgió, en primer lugar, la necesidad psicológica de mantener y alimentar esos contactos y, a continuación, poco a poco, esas redes interpersonales fueron creciendo y ampliándose hasta convertirse en algo más serio y organizado (Campos, 2008).

\subsection{4 ¿Cuándo y dónde?}

El origen de las redes sociales se remonta a 1995 cuando Randy Conrads creó el sitio classmates.com para recuperar o mantener el contacto con antiguos compañeros de colegio, instituto o universidad. Aun así, la primera red social identificada como tal en una web comenzó su andadura en 1997 en Estados Unidos y se llamó Sixdegrees.com.

En esa red los usuarios podían darse de alta, crear sus propios perfiles, elaborar una lista con sus amigos y también establecer contacto con otros usuarios mediante el envío de mensajes de texto. Fue a partir de 1998 cuando los usuarios empezaron a poder navegar por medio de los amigos de sus amigos (Monsoriu, 2009), al igual que ocurría en classmates.com. Con cuatro o cinco años de experiencia estas redes de relaciones sociales evolucionan hacia mayores organizaciones profesionales, con características de nuevos modelos de comunicación. 
Antes de la irrupción de Sixdegrees.com en 1997 ya existían perfiles en los que los usuarios mostraban información de tipo personal. Son ejemplos los portales especializados en la búsqueda de pareja o los primeros sistemas de mensajería instantánea como el ICQ. En todas estas plataformas también era posible crear listas de amigos, aunque a diferencia de las redes sociales, no eran públicas para el resto de usuarios y, a pesar de que ofrecían determinadas aplicaciones de índole social, no pueden considerarse redes sociales.

En 2000 Sixdegrees.com se vio obligada a cerrar debido, en parte, a la falta de confianza de los usuarios para contactar con otros a través de Internet. Al mismo tiempo, los responsables de las empresas que daban soporte a las diferentes redes sociales habían observado cómo la publicidad era el principal sustento económico de sus negocios y, en consecuencia, entre 1997 y 2001 comenzaron a mostrar anuncios en sitios como Friends, BlackPlanet, AsianAvenue o MiGente, donde las personas registradas ya diferenciaban en sus perfiles información personal, profesional y destinada a la búsqueda de pareja (Monsoriu, 2009).

En 1999 LiveJournal.com integra un sistema de mensajería instantánea que podía ser utilizado entre los mejores amigos de cada usuario. Un año después la comunidad virtual sueca LunarStorm actualizó sus prestaciones para incluir listas de amigos, libros de invitados y una especie de blog y en 2001 la red coreana Cyworld añadió desarrollos propios de una red social. También en 2001 Ryze.com, surgida en el ambiente tecnológico de San Francisco, echó a andar un sistema de ayuda a los usuarios para clasificar a sus contactos de negocios. Siguiendo esa misma tendencia aparecieron otras iniciativas como Tribe. net, LinkedIn o Friendster que también vinculaban la esfera personal con la profesional, aunque su evolución fue muy dispar en función del nicho de mercado al que se enfocaban.

La verdadera eclosión de las redes sociales se produjo de manera cronológica entre 2003 (con la aparición de Myspace) y 2006, "casi al mismo tiempo que las empresas y los profesionales de Internet empiezan a superar la resaca de la crisis de la llamada burbuja punto.com de 2001. Con la aparición de Myspace se le brindó al navegante la posibilidad de crear páginas personales de forma gratuita y relacionarse con otros usuarios, de manera que se potencia el componente social de la información difundida, con el añadido de que desde el primer momento se le concedió mucha importancia al contenido multimedia (Sixto, 2013).

Es en 2003 cuando la barrera social de acceso a Internet empieza a estar superada, a mediados de año existían más de 650 millones de usuarios en todo el mundo y el índice de penetración de la red superaba el 26 \% en América y Europa:

Tabla 2. Índice de penetración de Internet en el mundo (2003)

\begin{tabular}{|l|c|c|c|}
\hline \multicolumn{1}{|c|}{ Región } & Población (2003) & Usuarios & $\begin{array}{c}\text { \% Población (penetra- } \\
\text { ción) }\end{array}$ \\
\hline África & 879.855 .500 & 8.073 .500 & $0,9 \%$ \\
\hline América & 864.854 .400 & 228.775 .858 & $26,5 \%$ \\
\hline
\end{tabular}


Desarrollo de las redes sociales como herramienta de marketing. Estado de la cuestión hasta 2015

\begin{tabular}{|l|c|c|c|}
\hline \multicolumn{1}{|c|}{ Región } & Población (2003) & Usuarios & $\begin{array}{c}\text { \% Población (penetra- } \\
\text { ción) }\end{array}$ \\
\hline Asia & 3.590 .196 .700 & 200.319 .063 & $5,6 \%$ \\
\hline Europa & 722.509 .070 & 190.297 .994 & $26,3 \%$ \\
\hline Oriente Medio & 259.318 .000 & 12.019 .600 & $4,6 \%$ \\
\hline Oceanía & 31.528 .840 & 13.058 .832 & $41,4 \%$ \\
\hline TOTAL MUNDIAL & 6.348 .262 .510 & 652.544 .847 & $10,3 \%$ \\
\hline
\end{tabular}

Fuente: elaboración propia a partir de los datos de Éxito Exportador a 22-07-2003. Revisado el 1 de marzo de 2009 desde Internet (http://www.exitoexportador.com/)

Google lanza Orkut en enero de 2004 y Yahoo $360^{\circ}$ aparece en 2005. Facebook, la red social con mayor número de usuarios en el mundo, nacía en la Universidad de Harvard, aunque de ahí no tardó en extenderse a otros campus y universidades hasta superar en número de usuarios a Myspace en agosto de 2008. Hay quien atribuye el éxito de Facebook fuera de los Estados Unidos a la decisión de traducir la plataforma a otros idiomas diferentes del inglés y ofrecerla en la lengua propia de cada país. Esta cuestión lingüística se considera, precisamente, el factor de éxito de otras redes nacionales posteriores como la japonesa Mixi o la española Tuenti.

Tabla 3. Usuarios que visitaron una red social en Europa y aumento porcentual

\begin{tabular}{|l|c|c|c|}
\hline \multicolumn{1}{|c|}{ País } & $\begin{array}{c}\text { Diciembre } \\
2007\end{array}$ & $\begin{array}{c}\text { Diciembre } \\
2008\end{array}$ & $\begin{array}{c}\text { Aumento } \\
\text { porcentual }\end{array}$ \\
\hline Alemania & 48,4 & 67,3 & 19 \\
\hline Austria & 38,8 & 49,7 & 11 \\
\hline Bélgica & 59 & 68,2 & 9,2 \\
\hline Dinamarca & 54,4 & 69,7 & 15,3 \\
\hline España & 62,8 & 73,7 & 10,8 \\
\hline Finlandia & 61,2 & 66,2 & 11,8 \\
\hline Francia & 52,2 & 63,9 & 5,8 \\
\hline Holanda & 57,2 & 63 & 7 \\
\hline Irlanda & 59,9 & 66,9 & 12,9 \\
\hline Italia & 56,5 & 69,3 & 4,8 \\
\hline Noruega & 54,2 & 58,9 & 7,2 \\
\hline Portugal & 65,7 & 72,9 & 1,4 \\
\hline Reino Unido & 78,4 & 79,8 & 17,4 \\
\hline Rusia & 46,1 & 63,5 & 4,1 \\
\hline Suecia & 61,3 & 65,4 & 11 \\
\hline Suiza & 53,7 & 64,7 & \\
\hline
\end{tabular}

Fuente: elaboración propia a partir de los datos de comScore World Metrix 


\subsection{5 ¿Por qué?}

Las particularidades y las posibilidades de desarrollo provocaron que algunos autores considerasen Internet como un elemento nuclear de la aparición de un nuevo tipo de marketing (cfr. Hoffman y Novak, 1996), surgido a partir de la transformación y reconstrucción de acciones de marketing y comunicación en un panorama caracterizado por los flujos intensivos de información que incorpora la utilización de Internet al enfoque relacional sustentado en una transformación de los flujos de relaciones entre la organización y su entorno.

Hace ya unos años que la industria de la publicidad es consciente del potencial de las redes sociales. En 2011 dedicó 4300 millones de euros a las redes, casi el doble que el año anterior. En España, por ejemplo, en ese mismo año se alcanzaron los 30 millones de euros (Plenum Media, 2013). Facebook acapara el $80 \%$ de los ingresos publicitarios en redes sociales, mientras que Twitter ha multiplicado sus ingresos publicitarios de 36 millones de euros a casi 400 millones.

El ejercicio del marketing a través de Internet presenta características comunes con el marketing tradicional y también otras particulares y diferenciales que, en ningún caso, se excluyen, sino que se complementan y refuerzan:

a) Los objetivos y los conceptos del marketing online son idénticos a los del marketing tradicional y, por tanto, este debe concebirse como una filosofía de actuación en la que se incluyen el marketing tradicional y las técnicas que utiliza.

b) El marketing online representa y supone un valor añadido sobre todo para las pymes, que pueden empezar a competir con las mismas armas que las más grandes. Unas y otras se verán sometidas a la virtud de la actualización continua que permite el ciberespacio.

c) Debe integrarse plenamente en la organización y en su estructura y, en este sentido, su utilización provoca un cambio en el enfoque y en el papel del público al que se dirige, puesto que el público deja de ser un receptor pasivo y se convierte en un receptor activo que generalmente busca y solicita la información que le interesa.

d) A día de hoy lo importante que es crear una estrategia de visual content marketing o marketing de contenidos visuales, para transformar a la marca en imágenes en acción que den una nueva dimensión a la empresa (Merodio, 2014).

En cualquier caso, el marketing online pretenderá desarrollar ventajas competitivas que satisfagan a los usuarios potenciales que entran en contacto con la organización a través de la red. Las ventajas afectan a las 4P, puesto que es por medio de ellas como la organización tiene capacidad de influencia en el esquema de gestión que pone en marcha, en la comunicación con sus públicos y con el mercado y en la obligatoria adaptación al espacio virtual.

Con respecto a los productos, Internet puede cambiarlos directamente de naturaleza si esto supone una adaptación a las necesidades del usuario o, bien, permitir que sea el 
propio usuario quien decida qué tipo de producto quiere consumir o configurar. La comunicación entre la organización y sus públicos aumenta y las relaciones con los clientes se consolidan. El cliente tiene la opción de elegir su producto a la carta y la empresa la opción de satisfacerle porque conoce mejor que nunca cuáles son sus verdaderas necesidades.

Con respecto al precio, lo habitual es que Internet reduzca los costes del proceso comercial y de la distribución de los productos, puesto que permite acercar al destinatario final. Los beneficios de las reducciones se pueden orientar hacia la práctica de descuentos y promociones que ayuden a mantener a los clientes actuales y a captar a los potenciales.

Con respecto a la distribución, Internet permite la reducción de sus costes, la apertura de tiendas virtuales y la implantación de sistemas de distribución mucho más rápidos. Sin embargo, la red también puede utilizarse únicamente para dar soporte a los distribuidores habituales y no como canal de venta, de modo que la organización proporcionará información sobre los productos, pero sin competir con los distribuidores tradicionales. Otro caso sería usar la red como complementaria de las existentes (vendiendo directamente o través de la red), aunque también es viable la desintermediación (vender directamente al consumidor final sin recurrir a los canales de distribución habituales). Otros sitios tienen como principal recurso la información y no los productos, es decir, venden información sobre el producto y no el producto en sí (infomediarios).

Con respecto a la promoción y a la comunicación, las organizaciones quedan igualadas ante los ojos del navegante. Las más pequeñas tienen ahora acceso a mercados inabarcables y las más grandes encuentran a las más pequeñas en el maremágnum de sus competidores. La red ha adquirido gran importancia como medio publicitario gracias a la inserción de elementos patrocinados, banners, etc. en sus sitios web. La tecnología permite contabilizar los usuarios que acceden a las webs de manera que, incluso, es posible aplicar un sistema de tarificación basado en el coste por impacto. Segmentar es mucho más rápido y más sencillo y asentar redes y crear comunidades una realidad.

Las estrategias de marketing online posibilitan realizar diferentes tipos de marketing en diversos lugares de la red:

a) En los portales corporativos.

b) A través de emailing.

c) En los enlaces patrocinados.

d) En los portales sociales.

Sin embargo, antes de realizar cualquier tipo de acción de marketing online la organización debe:

a) Establecer una conexión inicial básica para explorar las posibilidades y los beneficios que le repuntará.

b) Analizar el impacto de Internet en la organización y en su sector de actuación para aprovechar las oportunidades, pero también para afrontar las amenazas. 
c) Definir la estrategia, los objetivos y las líneas de actuación: ¿cómo mejorar la comunicación? ¿cómo estar presente en Internet? ¿cómo desarrollar un programa de marketing de relaciones?

d) Evaluar los riesgos. No todo el monte es orégano. Habrá que pensar en la forma de conexión más adecuada, en la inversión requerida.

e) Una vez planificada habrá que implantar la estrategia y una vez implantada habrá que controlar y seguir los resultados.

Poner en marcha una estrategia de marketing online exige una planificación previa donde los objetivos estén marcados, los públicos seleccionados y el mensaje deliberado. Pero hay más. Woolf (1999) entiende que todo ser humano aspira a ser reconocido. Quizá toda organización también. Los privilegios y las recompensas exclusivas de cierto valor intrínseco responden a esta aspiración y por ello son muy apreciados. Sin embargo, al día de hoy con el reconocimiento no basta, se pretende la fidelización.

Cuando la fidelización aspira a ser perenne debe ejecutarse como una actuación estratégica que debe atender siempre y en primer lugar al usuario. Numerosos programas que recompensan a ejecutivos o a clientes fieles han resultado decepcionantes, ya que a menudo han sido implantados a todo correr para responder a un competidor, no han tenido un impacto visible en el mercado y han sido una fuente de gastos añadidos nada despreciables (Day, 1999). Parece lógico, entonces, que las estrategias ganadoras sean las desarrolladas por quien va a mantener esa diferenciación permanente.

Uno de los objetivos primordiales del marketing online es, pues, la fidelización de los usuarios. Fidelizar es conservar la clientela adquirida, sin más. Se opone por definición al principio de prospección, dedicado al reclutamiento de clientes (Lehu, 2001: 35). El desarrollo de una estrategia de fidelización se fundamenta en su rentabilidad potencial, puesto que permite estabilizar la actividad de la organización. Para que sea eficaz tiene que ofrecer al usuario un privilegio que no pueda obtener en otra parte, es decir, debe ser una apuesta por la exclusividad. De ahí la importancia del nombre de la marca.

\section{Conclusiones finales}

En el desarrollo de este artículo se relacionan las características y ventajas que supone para una organización actual la implementación de una estrategia correcta y adecuada en medios sociales. Ya no hay duda de que el panorama empresarial y la relación entre marcas y clientes han cambiado y, de hecho, las nuevas tecnologías como las redes sociales han dado mayor información a los consumidores que se traduce en poder de decisión a la hora de comprar un producto o servicio (Merodio, 2014). No obstante, como punto final y a modo de conclusión, resumimos de manera esquemática los principales beneficios que implica la puesta en marcha del Plan de Medios Sociales dentro de un sistema de gestión empresarial:

a) Creación de un punto de encuentro para los clientes potenciales, lo que permite compartir experiencias e ideas con redes personales integradas por miles de usuarios. 
b) Dar a conocer los productos a una red segmenta de usuarios que son completamente receptivos a esa información y que la siguen en tiempo real.

c) Aumento de la imagen de marca. La presencia en redes sociales es una demostración de la apuesta por las nuevas tecnologías y también por la transparencia.

d) Influencia positiva en el posicionamiento SEO, puesto que se generan enlaces y conversaciones en tiempo real.

e) Incremento de la presencia en red y contribución a la generación de tráfico de calidad hacia el sitio web.

f) Reducción de costes empresariales en medios de comunicación y en publicidad.

g) Generación de mayor tráfico hacia la el portal corporativo gracias al aumento de los enlaces a la web y a la fidelización de los usuarios de las redes.

h) Posibilidad de monitorizar todo lo ocurrido con la marca a través de diferentes herramientas creadas para tal fin.

\section{Bibliografía}

Campos, F. (2008). Las redes sociales trastocan los modelos de los medios de comunicación tradicionales. Revista Latina de Comunicación Social, 63, 1-8.

Day, G. (1999, Abril 30). Instaurer des relations durables. Les Echos, suplemento L'Art du Marketing, 3, pp. 66-70.

Dunbar, R.; Gamble, C. y Gowlet, R. (2009). Social Brain, Distributed Mind. Nova York: Oxford University Press.

Fages-Ramió, R. (2008). Actitud 2.0: la política más allá de los blogs. En IV Congreso Internet, Derecho y Política (IDP). Software social y Web 2.0: Implicaciones jurídico-políticas. Universitat Oberta de Catalunya. Revisado el 18 de noviembre de 2010 desde el monográfico en línea de IDP. Revista de Internet, Derecho y Política, 7, 19-25.

Hoffman, D. y Novak, T. (1996). Marketing in hypermedia computer-mediated environments: conceptual foundations. Journal of Marketingk, 60, 50-68.

Interactive Adverstising Bureau (IAB) (2009). Libro Blanco de IAB. La comunicación en medios sociales (vol. 8). Madrid: Edipo S. A. Revisado el 21 de octubre de 2010 desde Internet: http://www. iabspain.net/

Lehu, J.-M. (2001). Fidelizar al cliente. Marketing, Internet e imagen de marca (Trad. de P. Ducher). Barcelona: Ediciones Paidós.

Merodio, J. (2014). Dos años de marketing digital \& Social Media. Revisado el 16 de marzo de 2015 desde Internet: file://C:/Users/Userl/Downloads/2-Anos-de-Marketing-Digital-amp-Social-Media. pdf.pdf

Miguel de Bustos, J. C. (2007). Cambios institucionales en las industrias culturales. Hacia una economía directa o reticular. Portal de la Comunicación del Incom-UAB. Revisado o 13 de julio de 2010 desde Internet: http://www.portalcomunicacion.com/esp/n _ aab _lec _ 3. asp?id _ llico=27 
Monsoriu, M. (2009). Manual de Redes Sociales en Internet. Aprende a usar Tuenti, Facebook, Fotolog, Myspace, etc. iMejor que tus hijos! Madrid: Creaciones Copyright.

Plenum Media (2013). The Internet Marketing School.

San Millán, E.; Medrano, Ma L. e Blanco, F. (2008). Social Media Marketing, Redes Sociales y Metaversos. En E. J. de Castro e J. Díaz (Coords.), Universidad, Sociedad y Mercados Globales (pp. 353-366). Madrid: Asociación Española de Dirección y Economía de la Empresa (AEDEM).

Sixto, J. (2011). La red social Tuenti. Análisis del modelo de comunicación y de la estrategia de marketing. Telos, Cuadernos de Comunicación e Innovación, 89.

Sixto, J. (2013). Las redes sociales como estrategia de marketing online. Lisboa: Editora Media XXI.

Túñez, M. y Sixto, J. (2011): Redes sociales, política y Compromiso 2.0: "La comunicación de los diputados españoles en Facebook, en Revista Latina de Comunicación Social, 66. La Laguna (Tenerife): Universidad de La Laguna, 210-246. Revisado el 8 de marzo de 2013, de http://www.revistalatinacs.org/11/art/930_Santiago/09_ Tunez.html DOI: 10.4185/RLCS-66-2011-930-210-246 / CrossRef link

Watts, D. J. (2002). Six Degrees: The Science of a Connected Age. Nova York, W. W. Norton $\&$ Company, Inc.

Woolf, B. (1999). Le marketing de la différence. París: Village Mondial. 